\title{
Antibody Isotypes for Tumor Immunotherapy
}

\author{
Anna Kretschmer Ralf Schwanbeck Thomas Valerius Thies Rösner
}

Division of Stem Cell Transplantation and Immunotherapy, Department of Medicine II, University Hospital Schleswig-Holstein and Christian-Albrechts-University, Kiel, Germany

\section{Keywords}

Cancer - Immune response - Immunoglobulin isotypes . Immunotherapy

\section{Summary}

Compared to the evolutionary diversity of antibody isotypes, the spectrum of currently approved therapeutic antibodies is biased to the human IgG1 isotype. Detailed studies into the different structures and functions of human isotypes have suggested that other isotypes than IgG1 may be advantageous for specific indications - depending on the complex interplay between the targeted antigen or epitope, the desired mode of action, the pharmacokinetic properties, and the biopharmaceutical considerations. Thus, it may be speculated that with the increasing number of antibodies becoming available against a broadening spectrum of target antigens, identification of the optimal antibody isotype for particular therapeutic applications may become critical for the therapeutic success of individual antibodies. Thus, investments into this rather unexplored area of antibody immunotherapy may provide opportunities for distinction in the increasingly busy 'antibody space'. Therefore, $\lg G, \lg A, \lg E$ as well as $\lg M$ isotypes will be discussed in this review.

(C) 2017 S. Karger GmbH, Freiburg

\section{Introduction}

During the evolution of antibody repertoires, the emergence of highly variable antigen binding regions is accompanied by the development of limited sets of constant heavy chains [1]. These constant heavy chains determine the antibody isotype (in humans IgA,
IgD, IgE, IgG, and IgM), which can be further classified for some isotypes (e.g. in humans as $\operatorname{IgG} 1$ to $\operatorname{IgG} 4$, $\operatorname{IgA} 1$ and $\operatorname{IgA2}$ ) $[2,3]$. Many of these antibody isotypes are polymorphic in different populations - creating antibody allotypes. Employment of the limited set of constant heavy chains endows the variable antigen binding regions with particular sets of effector functions. These effectors functions are recruited e.g. by interactions with other soluble proteins (e.g. C1q of the complement cascade) or with specialized receptors on immune effector cells. In addition to classical Fc receptors for IgA, IgE and IgG [4-6], a receptor for IgM [7], a common receptor for IgA and $\operatorname{IgM}(\mathrm{Fca} / \mu \mathrm{R})[8]$, and a family of Fc receptorlike molecules (FcRL) have been distinguished [9].

Antibodies of various isotypes and their respective receptors on effector cells constitute complex networks, which link the adaptive and innate immune systems. These networks are partially conserved between different species, even though also many critical differences have evolved [10]. These species specific characteristics need to be considered in the interpretation of results from in vivo experiments [11, 12]. For example, humans express Fc receptors for which no functional homologs were found in mice (e.g. Fc $\gamma$ RIIIb or FcaRI). Additionally, homologous Fc receptors may be expressed on different effector cell types in men and mice. Importantly, also non-human primates display significant differences in their Fc receptor repertoire, which may affect, e.g., toxicology studies with human antibodies [13]. In addition to their different recruitment of effector functions, antibody isotypes also display considerable differences in their pharmacokinetic properties (see below), which may determine their suitability for particular clinical applications.

All human isotypes consist of heterodimers of heavy and light chains, which are typically paired by differently arranged disulfide bonds (fig. 1). Both light and heavy chains contain one variable domain ( $\mathrm{vL}$ and $\mathrm{vH}$, respectively). Light chains contain one constant domain ( $\mathrm{cL}$ ), while the number of constant domains for heavy chains is four for IgE and IgM ( $\mathrm{cH} 1-4)$ and three for all other isotypes $(\mathrm{cH} 1-3)$. The different heavy chains govern functional and

\section{KARGER}

(๑) 2017 S. Karger GmbH, Freiburg

Fax +497614520714 
$\lg G 1$

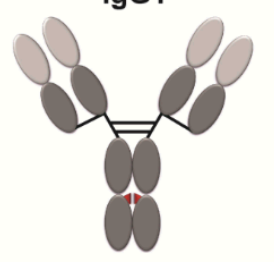

$\lg \mathrm{E}$

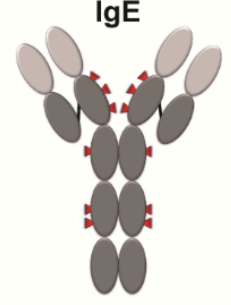

Pentameric

IgM

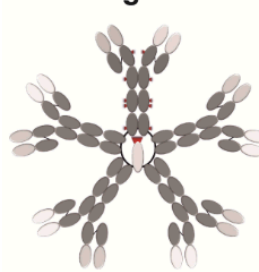

$\lg G 2$

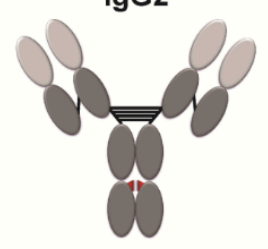

$\lg \mathrm{A} 1$
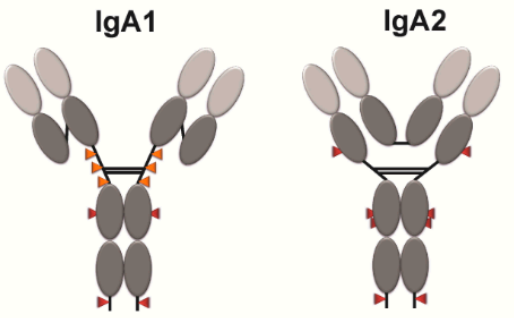

Dimeric IgA2

$\lg \mathbf{3} 3$

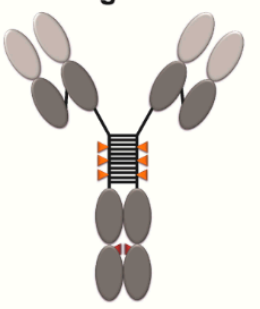

$\lg G 4$
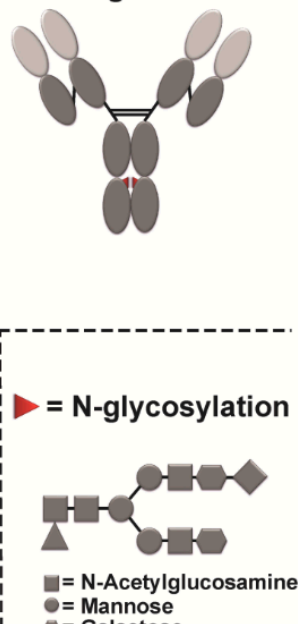
= Mannose $=$ Salactose $\Delta=$ Fucose

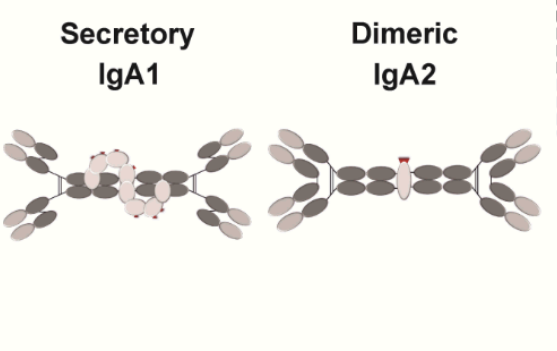

Fig. 1. Schematic representation of antibody isotypes and subclasses.

Variable regions are marked by $\bullet$, while constant regions are depicted in $\bullet$. Interchain disulphide bridges are shown by $\mid$. IgG subclasses and IgE antibodies only occur as monomers, while both IgA subclasses exist either as monomers or connected by the $\mathrm{J}$ chain (0) as dimers. Furthermore, IgA may also interact with plgR to form secretory IgA e.g. secretory IgA1. In contrast to the other isotypes, IgM antibodies solely exist as multimers, primarily as pentamers. $\mathrm{N}$-glycosylation sites are depicted by $\bullet$. O-glycosylation sites are marked by $\downarrow$. pharmacokinetic properties of the respective antibodies, while the functional differences between the two human light chains ( $\kappa$ or $\lambda$ ) have not been elucidated.

In addition to sequence differences in their constant domains, antibody isotypes differ significantly in their hinge regions. Thus, e.g. the length of the hinge and the number and orientation of disulfide bonds differs between isotypes, leading to variable flexibility between the two Fab arms and between Fab and Fc regions. These differences in the hinge region affect $\mathrm{Fc}$ receptor binding and Fcmediated effector functions, but may also impact the Fab-mediated, direct effector mechanism of antibodies [14] - as outlined in more detail for IgG2 and IgG3 isotypes in particular.

Antibody isotypes furthermore differ significantly in their glycosylation patterns. With the exception of IgG3 and IgA, which contain between 6 and 10 O-glycsoylation sites in their hinge regions, all other isotypes carry only varying amounts of N-glycosylation. While all IgG isotypes are $\mathrm{N}$-glycosylated at position $\mathrm{N} 297$, which is rather buried in the protein structure, other isotypes typically contain different numbers of $\mathrm{N}$-gylcosylation sites (fig. 1), which are often more exposed (e.g. in IgA).

\section{$\lg \mathbf{1} 1$}

Almost 30 years ago Brüggemann et al. [15] analyzed different human antibody isotypes and subclasses for their potential to activate complement to mediate complement-dependent cytotoxicity (CDC) and to recruit effector cells for antibody-dependent cellular cytotoxicity (ADCC) against human target cells. Based on their observations, IgG1 appeared as the most promising antibody isotype for tumor immunotherapy. In addition to these and many other in vitro results, human IgG1 antibodies were also effective in mouse models, since human IgG1 binds well to activating murine Fc $\gamma$ receptors on effectors cells. Apart from its promising effector functions, IgG1 antibodies were demonstrated to interact well with the human, but also with the murine neonatal Fc receptor (FcRn). Binding to FcRn protects IgG1 molecules from degradation and thereby extends their serum half-life compared to non-FcRn-binding isotypes [16]. Additionally, human IgG1 antibodies demonstrated favorable biotechnological characteristics such as high production rates in transfectoma cells (e.g. Chinese hamster ovary $(\mathrm{CHO})$ cells), easy and cost-effective purification (e.g. by protein $\mathrm{A}$ 
Table 1. List of approved monoclonal antibodies for tumor therapy and their isotype/subclass

\begin{tabular}{|c|c|c|c|c|c|}
\hline Antibody & Tradename & Target & Format & Indication & Year of Approval \\
\hline Rituximab & MabThera & $\mathrm{CD} 20$ & chimeric IgG1 & non-Hodgkin's lymphoma & 1997 \\
\hline Trastuzumab & Herceptin & HER2 & humanized IgG1 & breast cancer & 1998 \\
\hline Alemtuzumab & Campath & CD52 & humanized IgG1 & chronic lymphocytic leukemia & 2001 \\
\hline Bevacizumab & Avastin & VEGF & humanized IgG1 & colorectal cancer & 2004 \\
\hline Cetuximab & Erbitux & EGFR & chimeric IgG1 & colorectal cancer & 2004 \\
\hline Ofatumumab & Arzerra & $\mathrm{CD} 20$ & human IgG1 & chronic lymphocytic leukemia & 2009 \\
\hline Ipilimumab & Yervoy & CTLA-4 & human IgG1 & metastatic melanoma & 2011 \\
\hline Pertuzumab & Perjeta & HER2 & humanized IgG1 & breast cancer & 2012 \\
\hline Obinutuzumab & Gazyva & $\mathrm{CD} 20$ & humanized IgG1 & chronic lymphocytic leukemia & 2013 \\
\hline Ramucirumab & Cyramza & VEGFR2 & human IgG1 & gastric cancer & 2014 \\
\hline Daratumumab & Darzalex & CD38 & human IgG1 & multiple myeloma & 2015 \\
\hline Elotuzumab & Empliciti & CS1 & humanized IgG1 & multiple myeloma & 2015 \\
\hline Dinutuximab & Unituxin & GD2 & chimeric IgG1 & neuroblastoma & 2015 \\
\hline Necitumumab & Portrazza & EGFR & human IgG1 & non-small cell lung cancer & 2015 \\
\hline Olaratumab & Lartruvo & PDGFRa & human IgG1 & soft tissue sarcoma & 2016 \\
\hline Atezolizumab & Tecenriq & PD-L1 & humanized IgG1 & urothelial carcinoma & 2016 \\
\hline Panitumumab & Vectibix & EGFR & human IgG2 & colorectal cancer & 2006 \\
\hline Nivolumab & Opdivo & PD1 & human IgG4 & melanoma & 2014 \\
\hline Pembrolizumab & Keytruda & PD1 & humanized IgG4 & melanoma & 2014 \\
\hline \multicolumn{6}{|c|}{$\begin{array}{l}\text { HER2 = Human epidermal growth factor receptor } 2 \text {; VEGF = vascular endothelial growth factor; EGFR = epidermal growth factor } \\
\text { receptor; CTLA-4 = cytotoxic T-lymphocyte-associated protein } 4 \text {; VEGFR2 = vascular endothelial growth factor receptor } 2 \text {; GD2 }= \\
\text { ganglioside G2; PDGFR } \alpha=\text { platelet-derived growth factor receptor } \alpha \text {; PD-L1 = programmed death-ligand } 1 ; \text { PD-1 = programmed cell } \\
\text { death protein } 1 .\end{array}$} \\
\hline
\end{tabular}

columns), and development of specific storage formulations for increased stability. These characteristics allowed the establishment of Good Manufacturing Practice (GMP) to obtain optimal therapeutic agents. From an economical point of view, these industrial procedures contributed to the prominent role of IgG1 antibodies in the clinic [17]. Importantly, human IgG1 antibodies are often used as backbone for Fc engineering strategies which aim to further improve effector functions, stability, or pharmacokinetic properties of therapeutic antibodies $[18,19]$.

From the initial clinical studies, it took almost 10 years until rituximab as the first therapeutic antibody for oncological treatment received FDA approval in 1997. Rituximab is a chimeric CD20-targeting antibody, which paved the way for the development of so far almost 20 chimeric, humanized or human IgG1 monoclonal antibodies being approved for different oncological indications during the following two decades (table 1). When ipilimumab was approved for the treatment of metastatic melanoma in 2011, the era for the so-called immune checkpoint blockers began [20]. However, also antibodies against these types of antigens may not merely act by 'blocking' cellular interactions. For example, the cytotoxic T-lymphocyte-associated protein 4 (CTLA-4) antibody ipilimumab also is of human IgG1 isotype and triggers Fc-mediated $\mathrm{T}$ regulatory cell depletion, at least in mouse models.

\section{$\lg$ G2}

The human IgG2 isotype is predominantly selected when neutralization of antigens (e.g. soluble cytokines) or inhibition of re- ceptor-ligand interactions are targeted, while Fc-mediated effector functions (e.g. ADCC and CDC) appear undesired. Currently, the epidermal growth factor receptor (EGFR) antibody panitumumab is the only approved IgG2 antibody for cancer immunotherapy. However, with the emergence of immune checkpoint blockade as therapeutic principle, many more IgG2 antibodies are currently in clinical trials - with some of them short before approval [21].

IgG2 has limited C1q binding activity, but can trigger CDC at high target antigen and high antibody concentrations [22]. Furthermore, human IgG2 is only capable of binding to Fc $\gamma$ RIIa (CD32a), but not to other activating $F_{c} \gamma$ receptors. Importantly, human IgG2 binding to Fc $\gamma$ RIIa is significantly affected by a functional single nucleotide polymorphism (SNP) in this receptor, leading to a single amino acid change at position 131 (histidine or arginine). This polymorphism impacts the functional activity of human IgG2 antibodies. Thus, the high affinity variant (131-His) of Fc $\gamma$ RIIa was demonstrated to induce anti-CD3-IgG2-mediated $\mathrm{T}$-cell activation and proliferation after cross-linking via myeloid cell engagement [23]. Furthermore, the human IgG2 EGFR antibody panitumumab was demonstrated to mediate ADCC by myeloid effector cells against EGFR-positive tumor cells [24]. A randomized phase III study showed that panitumumab was non-inferior to the EGFR IgG1 antibody cetuximab in regard to overall survival [25]. Further studies need to address the impact of the Fc $\gamma$ RIIa polymorphism on the efficacy and potential toxicity of human IgG2 antibodies in cancer immunotherapy across different target antigens.

Recently, White et al. [26] analyzed the activity of immune stimulatory CD40 monoclonal antibodies of IgG2 isotype. In con- 
trast to other IgG subclasses, IgG2 antibodies displayed Fc receptor-independent stimulatory activity. Furthermore, they showed that this activity was provided by an IgG2 subfraction, IgG2B, but not by the IgG2A isoform. IgG2B is characterized by a unique arrangement of disulfide bonds in the hinge region. Other studies investigating $\mathrm{Fc}$-independent activity of rituximab reported that an IgG2 version of this antibody triggered programmed cell death more effectively than its IgG1 version [27]. Further studies in the structural and functional relationships of these effects may enable a new field of antibody engineering and can increase the potential of IgG2-related monoclonal antibodies for cancer immunotherapy.

\section{IgG3}

The interest in IgG3 as a therapeutic antibody isotype was stimulated following observations that an anti-HIV-specific IgG3 response was correlated with improved disease control and longer survival [28]. Antibodies of the IgG3 subclass were long known to exhibit strong Fc-mediated effector functions in vitro. For example, hapten-directed IgG3 antibodies were able to induce ADCC as well as CDC very effectively [15]. Interestingly, IgG3 antibodies showed an increased ability to induce $\mathrm{C} 1 \mathrm{q}$ binding and were more effective in Fc receptor binding than their IgG1 counterparts. Detailed analyses of IgG antibodies and their ability to activate the complement system demonstrated the superior efficacy of complement activation by the IgG3 isotype, particularly when epitope densities were lower $[22,29]$. Furthermore an IgG3 version of cetuximab was able to activate complement in contrast to the parental IgG1 antibody - with CD55 being the main regulator of IgG3induced complement activation [30].

Despite these promising biological activities, no IgG3 antibody has entered the clinic so far. This is probably explained by manufacturing issues: IgG3 antibodies cannot be purified by protein A chromatography, have a tendency to form aggregates, and carry $\mathrm{O}$ linked glycans in their extended hinge region. Furthermore, most IgG3 allotypes are not recycled by FcRn - leading to a serum halflife of approximately 7 days for IgG3, compared to 21 days for other IgG isotypes. However, Stapleton et al. [31] characterized an IgG3 allotypic variant, which contains an amino acid exchange at position 435 (arginine to histidine), which lead to effective FcRn transport and increased serum half-life.

Recently, Bournazos et al. [32] generated an engineered bispecific antibody for broad HIV neutralization. For improvement of the neutralization efficacy, the hinge region of an IgG3 was grafted onto the backbone of an IgG1 antibody. To further increase the flexibility of this molecule, all but the lowest two cysteines in the hinge region were exchanged by serine, thereby leading to an open conformation of this new molecule. In comparison to the parental unmodified antibody, the IgG3 open-hinge molecule was significantly more effective in HIV-1 neutralization. Further studies need to address the impact of these hinge engineering approaches for the generation of novel antibodies, especially under the aspect of neutralization or Fc-mediated effector functions.

\section{$\lg \mathbf{9} 4$}

IgG4 is commonly regarded as a non-activating antibody isotype in immunotherapy. Experiments performed by Brüggemann et al. [15] displayed the low activity of IgG4 to induce CDC as well as ADCC. Nevertheless, antibodies of the IgG4 subclass bind to activating $\mathrm{Fc} \gamma$ receptors - in particular to $\mathrm{Fc} \gamma \mathrm{RI}$ (CD64). While the affinity of IgG4 to Fc $\gamma$ RI was similar to that of IgG1 and IgG3, the affinities for Fc $\gamma$ RII $(\mathrm{a} / \mathrm{b} / \mathrm{c})$ and $\mathrm{Fc} \gamma \mathrm{RIIIa}(\mathrm{CD} 16 \mathrm{a})$ were lower [11]. Thus, a human IgG4 antibody against CD20 was able to induce ADCC against human B cells by engaging mononuclear effector cells [13].

In contrast to other antibody isoforms, the biology of IgG4 is characterized by a unique process called Fab arm exchange [33]. During this process half-molecules are formed - consisting of one heavy and one light chain, which are able to recombine with other half-molecules. Thereby, natural monovalent bispecific antibodies are formed, which may explain the biology and pathophysiology of IgG4 in health and disease [34].This Fab arm exchange was also documented to occur with a therapeutic IgG4 antibody, which exchanged Fab arms with natural IgG4 antibodies from the serum [35]. Fc engineering studies demonstrated that this Fab arm exchange can be prevented by a serine 228 proline (S228P) mutation, which stabilizes the IgG4 hinge and which is employed in most currently approved or evaluated therapeutic IgG4 antibodies. For example, two monoclonal IgG4 antibodies (pembrolizumab and nivolumab) were recently approved for immune checkpoint blockade. Both of these programmed cell death protein 1 (PD-1) monoclonal antibodies are mediating their therapeutic efficacy by blocking PD-1 and programmed death-ligand 1/2 (PD-L1/L2) interactions, leading to increased anti-tumor T-cell responses [20]. Since PD-1 antibodies, in contrast to PD-L1 antibodies, were shown to mediate their efficacy independently from $\mathrm{Fc} \gamma$ receptors [36], IgG4 appeared to be a reasonable IgG subclass for this therapeutic strategy.

While uncontrolled Fab arm exchange constituted a problem for IgG4 antibodies as therapeutic agents, it also opened up a new way to design bispecific antibodies. Introduction of two different matching mutations (K409R/F405L) into the Fc backbones of two parental IgG1 antibodies targeting different antigens resulted in the controlled formation of bispecific antibodies. These mutations are located in the $\mathrm{CH} 3$ domains and are responsible for the efficient and directed Fab arm exchange between the two parental IgG1 antibodies [37].

\section{IgA Antibodies}

Despite the success of therapeutic antibodies of the IgG isotype, research on alternative antibody isotypes for tumor immunotherapy continues. Antibodies of the IgA isotype were particularly effective in recruiting myeloid effector cells (monocytes/macrophages and granulocytes) for ADCC [38-40] while natural killer cells (NK cells) are not activated by IgA antibodies. Physiologically, 
$\operatorname{IgA}$ antibodies are the first line of immune defense against pathogens at mucosal surfaces [41]. Two different isoforms - IgA1 and IgA2 - are characterized in men (fig. 1), which share many key characteristics with IgG antibodies. However, IgA antibodies differ in the number of glycosylation sites, the length of their hinge regions, and the number and position of disulfide bridges within the molecules (fig. 1). Furthermore, IgA can form dimeric and secretory isoforms. Dimeric IgA is produced by mucosal plasma cells by connecting the tailpiece cysteines of two monomeric IgA molecules covalently with the so-called joining (J) chain. Dimeric IgA can then bind to the polymeric immunoglobulin receptor ( $\mathrm{pIgR}$ ) on the basolateral surface of mucosal epithelial cells. Bound dimeric IgA is then transported by transcytosis through epithelial cells to the luminal site of mucosal surfaces, where secretory IgA is released by proteolytic cleavage of pIgR. Thus, secretory IgA consists of J-chain-connected dimeric $\operatorname{IgA}$ and the associated secretory component (SC), which is an extracellular part of the pIgR [41].

In addition to their potent activity in recruiting myeloid effector cells for ADCC, IgA antibodies against CD20 triggered CDC against lymphoma cells [40]. Fab-mediated effector functions of monomeric IgA antibodies were similar to IgG antibodies, but were enhanced when dimeric IgA antibodies were compared with monomeric molecules [38]. In vivo experiments in different xenoand syngeneic human FcaRI transgenic mouse models demonstrated significant anti-tumor activity of an EGFR-directed human IgA2 antibody, although its serum half-life was short [42]. Additional studies suggested that the short serum half-life was triggered by asialo-glycoprotein receptor(ASGPR)-mediated elimination of the therapeutic antibody in the liver. To overcome this limitation, an Fc-engineered IgA2 molecule was developed, which demonstrated improved stability and a longer serum half-life translating into higher in vivo efficacy of the engineered compared to the parental IgA molecule [43]. Also IgA antibodies against human epidermal growth factor receptor $2 /$ neu (HER2/neu) or CD20 demonstrated in vitro and in vivo efficacy $[40,44]$. Despite these promising preclinical activities, IgA antibodies have currently not been introduced into clinical studies.

\section{$\lg M$}

Like other immunoglobulin isotypes, monomeric IgM molecules are composed of heavy and light chain heterodimers, which are covalently connected via disulfide bridges. However, serum IgM antibodies are predominantly pentameric molecules which are interconnected by the J-chain (fig. 1). As described for IgA, binding of pentameric IgM to the $\mathrm{pIgR}$ and its transport through epithelial cells leads to the formation of secretory IgM at mucosal surfaces. Nevertheless, IgM antibodies are mostly found as pentameric IgM in the circulation. IgM is produced by either B1 lymphocytes as 'natural antibodies' without being exposed to antigenic stimuli or by B2 lymphocytes after immunization as a defense mechanism against invading pathogens. Natural antibodies recognize a variety of pathogenic molecules such as nucleic acids, lipids and proteins, which are phylogenetically conserved and which were not encountered previously. Thus, IgM antibodies close the gap that arises after the first contact of potential pathogens and the first adaptive response of the immune system [, 45]. IgM antibodies and their pentameric structure are ideal activators of the complement system. Recently, Michaelsen and colleagues [46] showed not only that serum and pentameric IgM are potent CDC inducers but also that secretory $\operatorname{IgM}$, which is transported via transcytosis to mucosal tissues, induced comparable levels of CDC. Furthermore, IgM-induced effector functions do not seem to be influenced by the association of the molecule with either J-chain or SC. The Fc receptor for IgM is called $\mathrm{F} c \mu \mathrm{R}$ and is found exclusively on lymphocytes (B, T and NK cells) in men and only on B cells in mice. $\mathrm{F} c \mu \mathrm{R}$ shows a unique immunoreceptor tyrosine-based inhibition motif (ITIM) and immunoreceptor tyrosine-based activation motif (ITAM) pattern suggesting that the receptor may have the ability to act as a dual signal transmitter [7]. However, rather little is known about the IgM FcR and its role in immunity.

Only few tumor-directed IgM antibodies have been moved into clinical trials. For example, a human IgM antibody (called PATSM6) is directed against a tumor-specific variant of the glucoseregulated protein 78 (GPR78) / heat shock $70 \mathrm{kDa}$ protein 5 (HSPA5). This antibody-mediated induction of apoptosis and, to a lower extent, CDC against multiple myeloma cells and was evaluated in a phase I trial regarding safety and tolerability in patients with relapsed or refractory multiple myeloma. PAT-SM6 demonstrated good tolerability and modest activity in this phase I study [47]. Another monoclonal IgM antibody, which was introduced into a phase I trial, was MORAb-028. This GD2 antibody was administered intra-tumorally in patients with metastatic melanoma (NCT01123304).

\section{$\lg \mathbf{E}$}

IgE antibodies are commonly associated with allergic or parasitic diseases. Monomeric IgE antibodies bind with high affinity to FceRI, which is predominantly expressed on mast cells, basophils, monocytes, and macrophages making them favorable effector cell populations for IgE-mediated tumor growth control. Upon antigen binding, FceRI is cross-linked and triggers degranulation and mediator release to induce acute allergic reactions or tumor cell killing. Complexed or target-bound IgE can bind to the low-affinity IgE receptor FceRII (CD23), which is expressed on dendritic cells, macrophages, and eosinophils. Unlike for IgG antibodies, inhibitory Fc receptors have not been described for IgE. Compared with IgG1, IgE has a short serum half-life of 1.5 days, whereas in tissues the half-life is prolonged to approximately 2 weeks due to binding to Fce receptor-expressing immune cells (reviewed in [48]).

Bridging allergy and cancer IgE antibodies were demonstrated to contribute to the natural immune surveillance of tumors. For example, elevated IgE levels were observed in serum samples of pancreatic cancer patients. Some of these IgE antibodies were found to be tumor antigen-specific and induced ADCC in pancre- 
atic cancer cell lines [49]. Thus, IgE antibodies against different target antigens such as HER2/neu, CD20, 4-hydroxy-3-iodo-5-nitrophenylacetic acid (NIP), or mouse Ly2 (CD8a) were generated, and their immunotherapeutic features were analyzed in vitro and in vivo. For example, Karagiannis and colleagues [50] investigated an IgE isoform of the MOv18 antibody (directed against the folate binding protein) in a human ovarian carcinoma xenograft model. They observed that the IgE antibody was not only superior to its IgG1 counterpart in prolonging survival of mice (together with human peripheral blood mononuclear cell as effector cells), which was demonstrated to be mediated by monocytes acting as effector cells for IgE-mediated ADCC and phagocytosis of tumor cells. The critical involvement of IgE in allergy and its role in inducing systemic type I hypersensitivity reactions (anaphylactic shock) raised concerns about the IgE antibody format for therapeutic use in clinical applications. However, several studies addressed this issue and concluded that systemic hypersensitivity reactions caused by tumor antigen-directed IgE antibodies may not occur in a therapeutic setting. Additionally, no evidence for systemic hypersensitivity reactions due to IgE antibody therapy was seen in various in vivo models (reviewed in [51]). As a result of these in vitro and in vivo observations, an ongoing phase I clinical trial evaluates the potential of IgE antibodies in cancer immunotherapy (NCT02546921).

\section{Discussion and Conclusions}

The great majority of currently approved antibodies in tumor therapy are of human IgG1 isotype. IgG2 and IgG4 isotypes are increasingly used when non-Fc-mediated effector functions are thought to be the predominant mode of action. Here, however, Fcengineered antibodies with completely silenced Fc receptor and complement binding are expected to become logical competitors. While also IgM and IgE isotypes are explored in early clinical trials, IgG3 and IgA antibodies have not entered clinical studies, although they display promising activity in preclinical models. One of the challenges for the future will be to equip the variable regions of a particular antibody with an optimally selected Fc part - depending on the expected mode(s) of action of this molecule. Antibody engineering strategies will provide additional opportunities to achieve this goal.

\section{Acknowledgment}

This work was supported by a grant (Va124/9-1) from the German Research Organization (DFG).

\section{Disclosure Statement}

The authors declared no conflict of interest.

\section{References}

1 Cooper MD: The early history of B cells. Nat Rev Immunol 2015;15:191-197.

2 Jefferis R: Isotype and glycoform selection for antibody therapeutics. Arch Biochem Biophys 2012;526:159-166.

3 Vidarsson G, Dekkers G, Rispens T: IgG subclasses and allotypes: from structure to effector functions. Front Immunol 2014;5:520.

4 Monteiro RC, Van De Winkel JG: IgA Fc receptors. Annu Rev Immunol 2003;21:177-204

5 Nimmerjahn F, Ravetch JV: Divergent immunoglobulin $\mathrm{G}$ subclass activity through selective $\mathrm{Fc}$ receptor binding. Science 2005;310:1510-1512.

6 Ravetch JV, Kinet JP: Fc receptors. Annu Rev Immunol 1991;9:457-492.

7 Kubagawa H, Oka S, Kubagawa Y, Torii I, Takayama E, Kang DW, Jones D, Nishida N, Miyawaki T, Bertoli LF, Sanders SK, Honjo K: The long elusive IgM Fc receptor, Fc $\mu$ R. J Clin Immunol 2014;34(suppl 1):S35-45.

$>$ Kinet JP, Launay P: Fca/ $\mu$ R: Single member or first born in the family? Nat Immunol 2000;1:371-372.

$\checkmark$ Maltais LJ, Lovering RC, Taranin AV, Colonna M, Ravetch JV, Dalla-Favera R, Burrows PD, Cooper MD, Davis RS: New nomenclature for Fc receptor-like molecules. Nat Immunol 2006;7:431-432.

10 Akula S, Mohammadamin S, Hellman L: Fc receptors for immunoglobulins and their appearance during vertebrate evolution. PloS One 2014;9:e96903.

11 Bruhns P: Properties of mouse and human IgG receptors and their contribution to disease models. Blood 2012;119:5640-5649.

12 Overdijk MB, Verploegen S, Ortiz Buijsse A, Vink T Leusen JH, Bleeker WK, Parren PW: Crosstalk between human IgG isotypes and murine effector cells. J Immunol 2012;189:3430-3438.
Hogarth PM, Anania JC, Wines BD: The Fc $\gamma \mathrm{R}$ of humans and non-human primates and their interaction with IgG: Implications for induction of inflammation, resistance to infection and the use of therapeutic monoclonal antibodies. Curr Top Microbiol Immunol 2014;382:321-352.

14 Beers SA, Glennie MJ, White AL: Influence of immunoglobulin isotype on therapeutic antibody function. Blood 2016;127:1097-1101.

15 Bruggemann M, Williams GT, Bindon CI, Clark MR, Walker MR, Jefferis R, Waldmann H, Neuberger MS: Comparison of the effector functions of human immunoglobulins using a matched set of chimeric antibodies. J Exp Med 1987;166:1351-1361.

16 Ghetie V, Ward ES: Multiple roles for the major histocompatibility complex class I-related receptor FcRn. Annu Rev Immunol 2000;18:739-766.

17 Wurm FM: Production of recombinant protein therapeutics in cultivated mammalian cells. Nat Biotechnol 2004;22:1393-1398.

18 Carter PJ: Potent antibody therapeutics by design. Nat Rev Immunol 2006;6:343-357.

19 Wirt T, Rosskopf S, Rösner T, Eichholz K, Kahrs A, Lutz S, Kretschmer A, Valerius T, Klausz K, Otte A, Gramatzki M, Peipp M, Kellner C: An Fc double-engineered CD20 antibody with enhanced CDC and ADCC activity. Transfus Med Hemother 2017;44:DOI: 10.1159/000479978.

20 Pardoll DM: The blockade of immune checkpoints in cancer immunotherapy. Nat Rev Cancer 2012;12:252264.

21 Reichert JM: Antibodies to watch in 2017. MAbs 2017; 9:167-181.
2 Garred P, Michaelsen TE, Aase A: The IgG subclass pattern of complement activation depends on epitope density and antibody and complement concentration. Scand J Immunol 1989;30:379-382.

23 Parren PW, Warmerdam PA, Boeije LC, Arts J, Westerdaal NA, Vlug A, Capel PJ, Aarden LA, van de Winkel JG: On the interaction of IgG subclasses with the low affinity Fc $\gamma$ RIIa (CD32) on human monocytes, neutrophils, and platelets. Analysis of a functional polymorphism to human IgG2. J Clin Invest 1992;90:1537-1546.

24 Schneider-Merck T, Lammerts van Bueren JJ, Berger S, Rossen K, van Berkel PH, Derer S, Beyer T, Lohse S, Bleeker WK, Peipp M, Parren PW, van de Winkel JG, Valerius T, Dechant M: Human IgG2 antibodies against epidermal growth factor receptor effectively trigger antibody-dependent cellular cytotoxicity but, in contrast to IgG1, only by cells of myeloid lineage. J Immunol 2010;184:512-520.

25 Price TJ, Peeters M, Kim TW, Li J, Cascinu S, Ruff P, Suresh AS, Thomas A, Tjulandin S, Zhang K, Murugappan S, Sidhu R: Panitumumab versus cetuximab in patients with chemotherapy-refractory wild-type KRAS exon 2 metastatic colorectal cancer (ASPECCT): A randomised, multicentre, open-label, non-inferiority phase 3 study. Lancet Oncol 2014;15:569-579.

26 White AL, Chan HT, French RR, Willoughby J, Mockridge CI, Roghanian A, Penfold CA, Booth SG, Dodhy A, Polak ME, Potter EA, Ardern-Jones MR, Verbeek JS, Johnson PW, Al-Shamkhani A, Cragg MS, Beers SA, Glennie MJ: Conformation of the human immunoglobulin G2 hinge imparts superagonistic properties to immunostimulatory anticancer antibodies. Cancer Cell 2015;27:138-148. 
27 Konitzer JD, Sieron A, Wacker A, Enenkel B: Reformatting rituximab into human IgG2 and IgG4 isotypes dramatically improves apoptosis induction in vitro. PloS One 2015;10:e0145633.

28 Banerjee K, Klasse PJ, Sanders RW, Pereyra F, Michael E, Lu M, Walker BD, Moore JP: IgG subclass profiles in infected HIV type 1 controllers and chronic progressors and in uninfected recipients of Env vaccines. AIDS Res Hum Retroviruses 2010;26:445-458.

29 Rosner T, Derer S, Kellner C, Dechant M, Lohse S, Vidarsson G, Peipp M, Valerius T: An IgG3 switch varian of rituximab mediates enhanced complement-dependent cytotoxicity against tumour cells with low CD20 expression levels. Br J Haematol 2013;161:282-286.

30 Rosner T, Lohse S, Peipp M, Valerius T, Derer S: Epidermal growth factor receptor targeting IgG3 triggers complement-mediated lysis of decay-accelerating factor expressing tumor cells through the alternative pathway amplification loop. J Immunol 2014;193:1485-1495.

31 Stapleton NM, Andersen JT, Stemerding AM, Bjarnarson SP, Verheul RC, Gerritsen J, Zhao Y, Kleijer M, Sandlie I, de Haas M, Jonsdottir I, van der Schoot CE, Vidarsson G: Competition for FcRn-mediated transport gives rise to short half-life of human IgG3 and offers therapeutic potential. Nat Commun 2011;2:599.

32 Bournazos S, Gazumyan A, Seaman MS, Nussenzweig MC, Ravetch JV: Bispecific anti-HIV-1 antibodies with enhanced breadth and potency. Cell 2016;165:1609_ 1620.

33 Schuurman J, Graus YF, Labrijn AF, Ruuls S, Parren PW: Opening the door to innovation. MAbs 2014;6: 812-819.

34 van der Neut Kolfschoten M, Schuurman J, Losen M, Bleeker WK, Martinez-Martinez P, Vermeulen E, den Bleker TH, Wiegman L, Vink T, Aarden LA, De Baets MH, van de Winkel JG, Aalberse RC, Parren PW: Antiinflammatory activity of human IgG4 antibodies by dynamic Fab arm exchange. Science 2007;317:1554-1557.

35 Labrijn AF, Buijsse AO, van den Bremer ET, Verwilligen AY, Bleeker WK, Thorpe SJ, Killestein J, Polman $\mathrm{CH}$, Aalberse RC, Schuurman J, van de Winkel JG, Parren PW: Therapeutic IgG4 antibodies engage in Fab-arm exchange with endogenous human IgG4 in vivo. Nat Biotechnol 2009;27:767-771.
36 Dahan R, Sega E, Engelhardt J, Selby M, Korman AJ, Ravetch JV: Fc $\gamma$ Rs modulate the anti-tumor activity of antibodies targeting the PD-1/PD-L1 axis. Cancer Cell 2015;28:285-295.

37 Labrijn AF, Meesters JI, de Goeij BE, van den Bremer ET, Neijssen J, van Kampen MD, Strumane K, Verploegen S, Kundu A, Gramer MJ, van Berkel PH, van de Winkel JG, Schuurman J, Parren PW: Efficient generation of stable bispecific IgG1 by controlled Fab-arm exchange. Proc Natl Acad Sci U S A 2013;110:5145-5150.

38 Dechant M, Beyer T, Schneider-Merck T, Weisner W, Peipp M, van de Winkel JG, Valerius T: Effector mechanisms of recombinant IgA antibodies against epidermal growth factor receptor. J Immunol 2007;179: 2936-2943.

39 Huls G, Heijnen IAFM, Cuomo E, van der Linden J, Boel E, van de Winkel JGJ, Logtenberg T: Antitumor immune effector mechanisms recruited by phage display-derived fully human IgG1 and IgA1 monoclonal antibodies. Cancer Res 1999;59:5778-5784.

40 Lohse S, Loew S, Kretschmer A, Jansen JHM, Meyer S, Ten Broeke T, Rosner T, Dechant M, Derer S, Klausz K, Kellner C, Schwanbeck R, French RR, Tipton TRW, Cragg MS, Schewe DM, Peipp M, Leusen JHW, Valerius T: Effector mechanisms of IgA antibodies against CD20 include recruitment of myeloid cells for antibody-dependent cell-mediated cytotoxicity and complement-dependent cytotoxicity. Br J Haematol 2017; doi: 10.1111/bjh.14624.

41 Woof JM, Russell MW: Structure and function relationships in IgA. Mucosal Immunol 2011;4:590-597.

42 Boross P, Lohse S, Nederend M, Jansen JH, van Tetering G, Dechant M, Peipp M, Royle L, Liew LP, Boon L, van Rooijen N, Bleeker WK, Parren PW, van de Winkel JG, Valerius T, Leusen JH: IgA EGFR antibodies mediate tumour killing in vivo. EMBO Mol Med 2013; 5:1213-1226.

43 Lohse S, Meyer S, Meulenbroek LA, Jansen JH, Nederend M, Kretschmer A, Klausz K, Moginger U, Derer S, Rosner T, Kellner C, Schewe D, Sondermann P, Tiwari S, Kolarich D, Peipp M, Leusen JH, Valerius T: An anti-EGFR IgA that displays improved pharmacokinetics and myeloid effector cell engagement in vivo. Cancer Res 2016;76:403-417.
44 Rouwendal GJ, van der Lee MM, Meyer S, Reiding KR, Schouten J, de Roo G, Egging DF, Leusen JH, Boross P, Wuhrer M, Verheijden GF, Dokter WH, Timmers M, Ubink R: A comparison of anti-HER2 IgA and IgG1 in vivo efficacy is facilitated by high $\mathrm{N}$-glycan sialylation of the IgA. MAbs 2016;8:74-86.

45 Gronwall C, Vas J, Silverman GJ: Protective roles of natural IgM antibodies. Front Immunol 2012;3:66.

46 Michaelsen TE, Emilsen S, Sandin RH, Granerud BK, Bratlie D, Ihle O, Sandlie I: Human secretory IgM antibodies activate human complement and offer protection at mucosal surface. Scand J Immunol 2017;85:43-50.

47 Rasche L, Duell J, Castro IC, Dubljevic V, Chatterjee M, Knop S, Hensel F, Rosenwald A, Einsele H, Topp MS, Brandlein S: GRP78-directed immunotherapy in relapsed or refractory multiple myeloma - results from a phase 1 trial with the monoclonal immunoglobulin $\mathrm{M}$ antibody PAT-SM6. Haematologica 2015;100:377-384.

48 Josephs DH, Spicer JF, Karagiannis P, Gould HJ Karagiannis SN: IgE immunotherapy: a novel concept with promise for the treatment of cancer. MAbs 2014; 6:54-72.

49 Fu SL, Pierre J, Smith-Norowitz TA, Hagler M, Bowne W, Pincus MR, Mueller CM, Zenilman ME, Bluth MH: Immunoglobulin $\mathrm{E}$ antibodies from pancreatic cancer patients mediate antibody-dependent cell-mediated cytotoxicity against pancreatic cancer cells. Clin Exp Immunol 2008;153:401-409.

50 Karagiannis SN, Bracher MG, Hunt J, McCloskey N, Beavil RL, Beavil AJ, Fear DJ, Thompson RG, East N, Burke F, Moore RJ, Dombrowicz DD, Balkwill FR, Gould HJ: IgE-antibody-dependent immunotherapy of solid tumors: cytotoxic and phagocytic mechanisms of eradication of ovarian cancer cells. J Immunol 2007; 179:2832-2843.

51 Leoh LS, Daniels-Wells TR, Penichet ML: IgE immunotherapy against cancer. Curr Top Microbiol Immunol 2015;388:109-149. 